Article

\title{
Effect of Design on the Evacuation Time for Large Arenas of Different Epochs
}

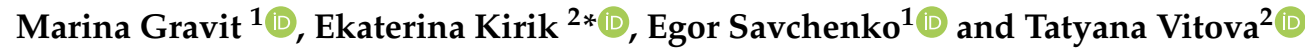 \\ 1 Peter the Great St. Petersburg Polytechnic University, St. Petersburg, 195251 Russia; marina.gravit@mail.ru \\ 2 Institute of Computational Modelling of the Siberian Branch of the Russian Academy of Sciences, \\ Krasnoyarsk, 660036 Russia; kirik@icm.krasn.ru \\ * Correspondence: gravit kirik@icm.krasn.ru
}

\begin{abstract}
The designs of two large arenas of different epochs are discussed, which are the most famous antique amphitheater the Roman Colosseum (Italy) and the modern Gazprom Arena stadium (St. Petersburg, Russia). 3D-computer models of the arenas have been built and evacuation of people has been simulated in the Sigma FS software (Russia). The arena designs are analyzed in terms of organizing pedestrian evacuation, a comparative analysis is made, and the specific characteristics affecting the evacuation time are established.
\end{abstract}

Keywords: arena; design; evacuation time ; fire safety ; computer simulation

\section{Introduction}

Arenas, as places of mass gathering, are high-risk facilities. A source of hazard is the simultaneous presence of thousands of people in them. The greatest danger is posed by the operation conditions with the simultaneous targeted pedestrian movement, including the stadium outflow after events and the emergency evacuation, e.g., during a fire case.

At the outflow, a key role is played by the design, i.e., the width, configuration and number of escape routes for leaving stands and a building in correlation with the arena capacity.

In case of fire, a part of routes can be blocked by the fire and smoke spreading along them. Then, it is necessary to re-route people, which generally increases the evacuation time, which, in turn, toughens the requirements for the fire resistance of a building structure and finishing materials for escape routes ${ }^{1}$.

Meanwhile, large arenas are a heritage of not only the contemporary world. In classical times, such arenas were also built; the most famous of them is the Roman Colosseum commissioned in 80 A.D. The Colosseum capacity estimates range from 40000 to 50000 people [1].

The aim of this study was to investigate the designs used when constructing the ancient and modern arenas in terms of organizing evacuation and to compare them using, in particular, the simulation of evacuation from the buildings under study. The examined arenas are the Roman Colosseum and the Gazprom Arena stadium in St. Petersburg (Russia).

Computer simulations of the pedestrian movement [2], [3] are rather popular nowadays and used to analyze the infrastructure during mass gathering events and operation of crowded places. In [4] there were explored three scenarios of the evacuation of music festival locations with a capacity of 65 thousand people. Pretorius et al. [5] analyzed, using video records, the Duisburg Love Parade electronic dance music festival crowed disaster in Germany (2010), which caused the deaths of 21 people from

1 For example, see Russian Technical regulations on fire safety requirements. Federal law No. 123-FZ of July 22, 2008. 
suffocation. The authors developed the scenarios, both similar to the real one and alternative, which were then simulated. The computational domain contained 26 thousand people. In [6] a system for real-time simulating the movement of people on the multi-purpose Dusseldorf Arena (Germany) is described. In [7] the authors took into account the pedestrian trajectories at the stadium. Wei et al. [8] studied the fire spread and evacuation simulation technology in a large stadium. The human movement simulations were used to analyze the safety of major religious events, for example, the hajj in Mecca (Saudi Arabia) [9], [10], [11], [12]. A number of works [13], [14], [15], [16] were devoted to the optimization of the operation of airports and metro and railway stations. An evacuation from of high-rise buildings could be planed with help of people movement simulation [17].

In the next section, we describe the investigated arenas and analyze their design features important for our study. Further, we present the results of the simulation of evacuation out of the Colosseum and Gazprom Arena stadium and compare the arenas using the obtained numerical characteristics. Finally, we end with the discussion of the results and make some concluding remarks.

\section{Description of the Arena Designs}

\subsection{Colosseum}

Among historians and architects, there has still been no consensus about the design features and appearance of an antique amphitheater. Therefore, in the description, we focus on the features that are essential for our study and build a model suitable for simulating the evacuation. In our work, we base on the Durm's architectural representations [1].

The Colosseum central part is an oval stage surrounded by a flat strip of seats; the ratio between the major and minor axes of the entire building is 1.22. An oval cone with seats is around the arena. It is based on 80 parting walls directed radially inward and interconnected by ring walls and arche rows. Between them, there are a corresponding number of radially directed crossings and staircases; ring galleries stretching along the entire amphitheater between the ring walls and arcades connect walkways and stairs. The exterior galleries of the 2 nd and 3 rd floors serve as lounges. The gallery height on the floors is $10-11 \mathrm{~m}$.

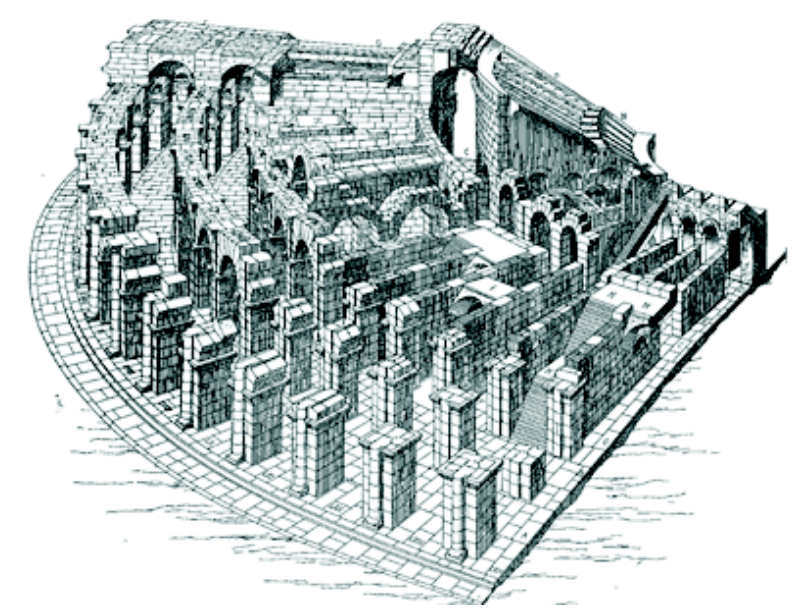

Figure 1. Schematic view of the Colosseum 1st floor (Gyuade) [1].

There are 80 arches along the outer perimeter that form 80 amphitheater entryways (Figure 1). The entrances/exits are located at the ground level (the so-called datum). Therefore, the evacuation can only occur top-down.

The amphitheater can be conventionally divided into three tiers (Figure 2), each containing under-stand galleries, stands, and walkways to the seats (Figure 3). It should be noted that the free 
area of each upper floor is smaller than that of the lower one. The access stairs are located in the under-stand space.

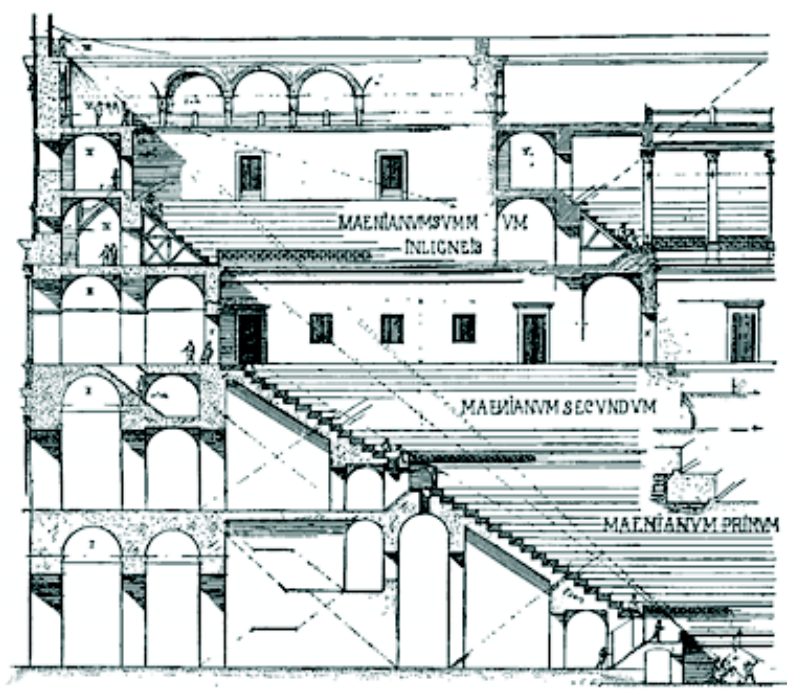

Figure 2. Schematic of the Colosseum architectural design according to the Durm's representations [1].

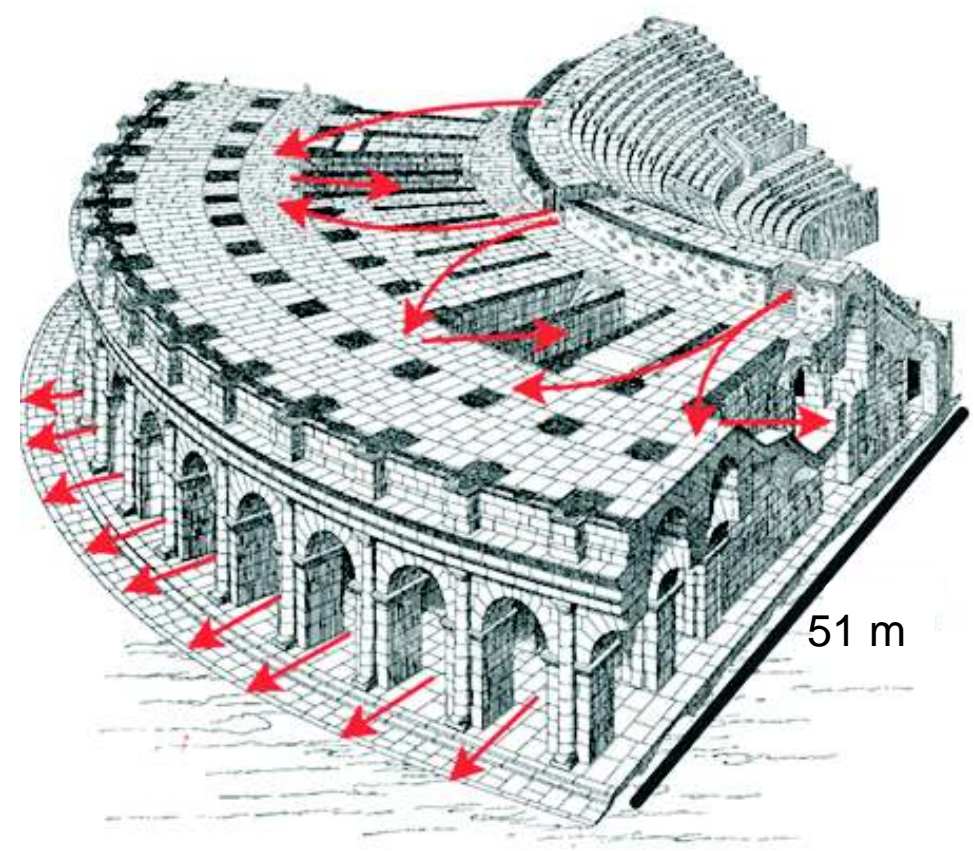

Figure 3. Schematic view of the Colosseum 2nd floor (Gyuade) [1].

The model was built assuming that the access to the ground-tier stands was mainly through the 2nd floor; to the second-tier stands, through the 3rd floor; and to the third-tier stands, through the 4th floor (the attitude of the latter is about +40.00). The first two tiers represent sequences of 20 stand rows and the upper tier contains 16 rows. The data on the maximum arena capacity reported by different authors are inconsistent and vary between 40 and 50 thousand audience members simultaneously [1], so the conventional number of people is 48,000 .

The Colosseum has the line-of-sight down stairs on both sides of each exit to the under-stand gallery (Figure 3). The stairs are uniformly distributed along the floor perimeter. The number of stairs is consistent with the number of exits to the under-stand space, i.e., is equal to the number of tier 
sectors. The stair path width along the axis of movement ranges from $2 \mathrm{~m}$ for descending from the upper tier of stands to the 3rd floor to $4.5 \mathrm{~m}$ in the lower part.

\subsection{Gazprom Arena Stadium}

The arena commissioned in late 2016 (Figure 4) is considered to be one of the most advanced football stadiums worldwide. In our description, we only focus on its characteristics important for the investigations, which were included in a 3D computer model of the building for simulating evacuation and analyzing the results obtained.

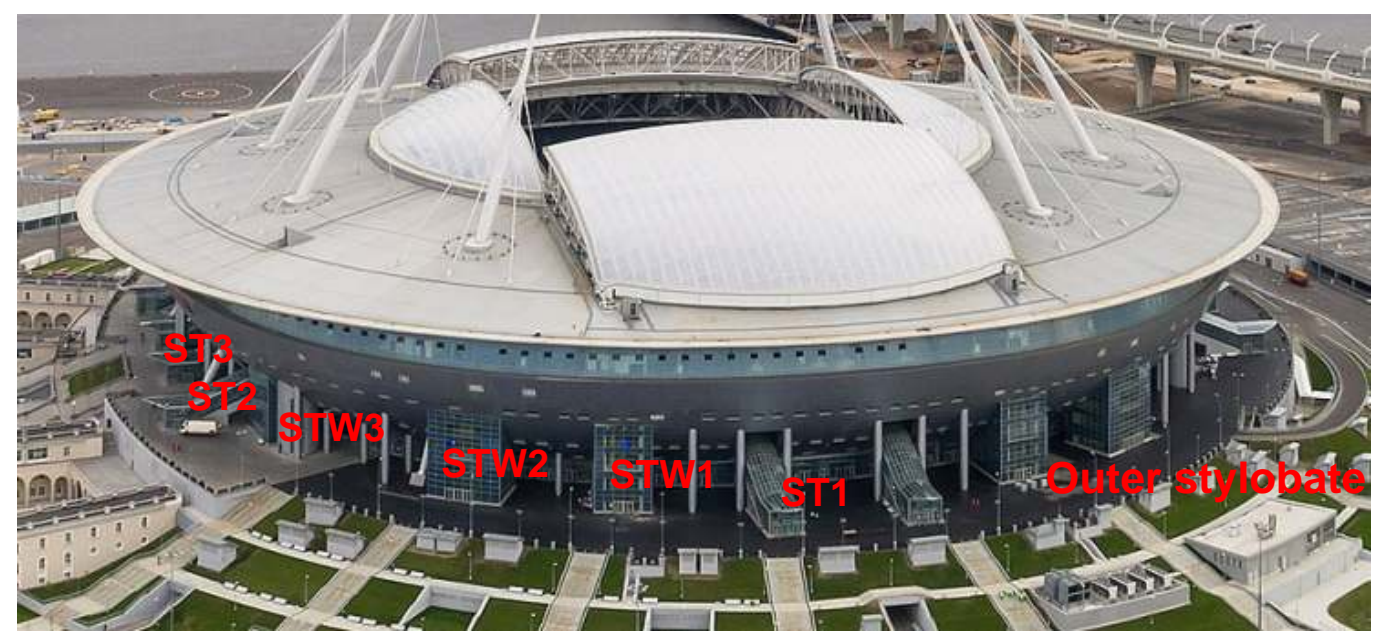

Figure 4. Northeast side view of the Gazprom Arena stadium.

According to the building specifications, a stadium bowl is designed for 68,000 seats, including temporary stands, which can be installed on the 3rd- and 7th-floor stylobates (Figure 5). The stadium capacity in the concert regime, when the field is involved, is increased to 80,000 people. The bowl consists of two (lower and upper) tiers. The height difference between the lower tier rows is almost 12 $\mathrm{m}$. There are exits (safety hatches) to the 2nd floor and to the inner stylobate located on the 3rd floor (the attitude is +14.55 ). The lower bowl is almost symmetrical relative to the minor axis of the field.

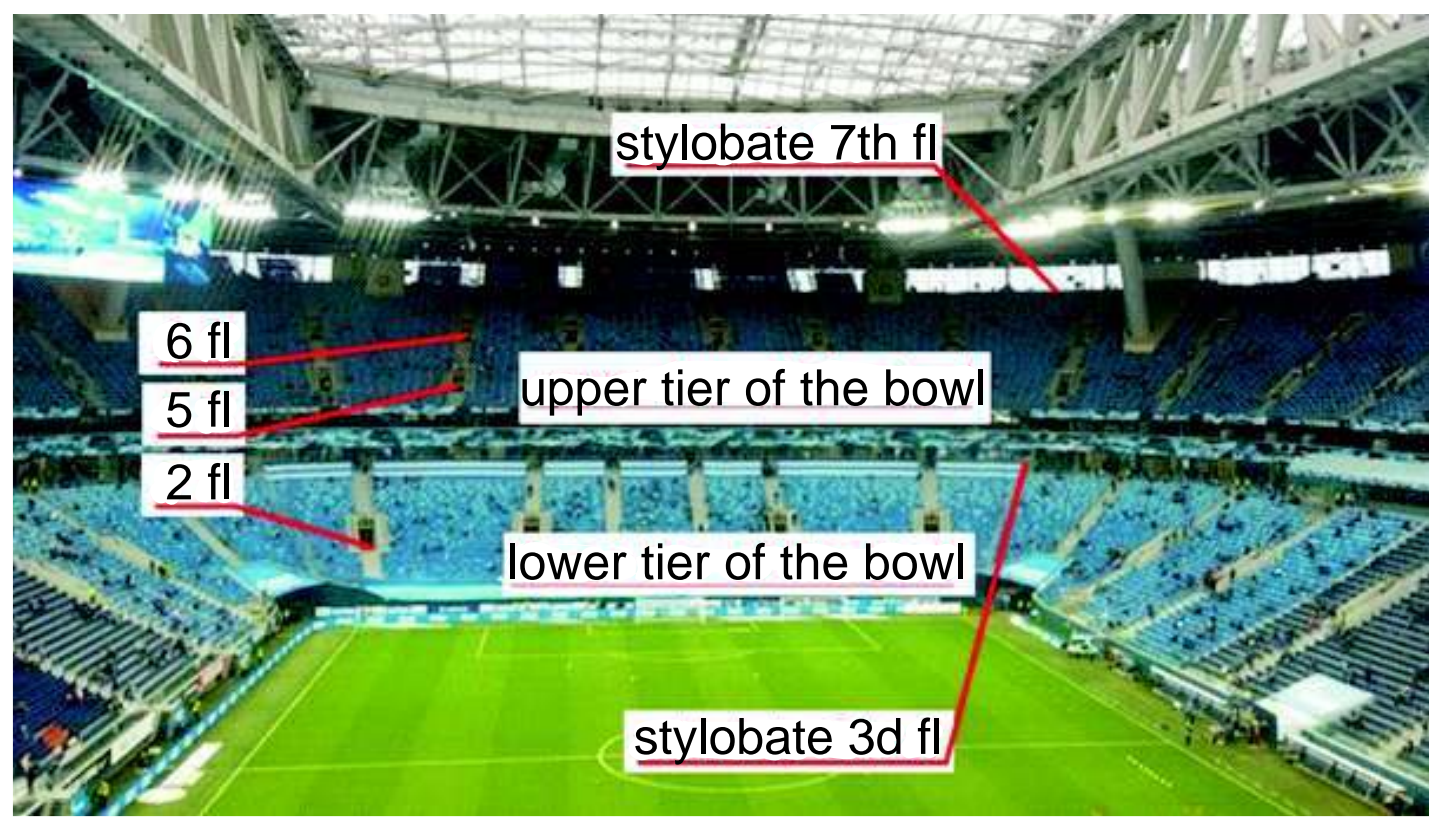

Figure 5. Gazprom Arena bowl view from stand B (north). 
The upper bowl (tier) rows have a height difference of $\sim 20 \mathrm{~m}$. There are exits (safety hatches) to the 5th (+25.2) and 6th (+32.85) floors. In addition, there are paths to the 7 th $(+42.45)$ floor, i.e., the upper inner stylobate. The top bowl can be considered symmetric with respect to both axes.

The emergency exits from the building for the lower bowl audience are located mainly on the 3rd floor (only the eastern-sector audience can exit outside directly from the 2nd floor below the 3rd-floor outer stylobate).

The exit outside from the upper bowl is also located at the 3rd-floor level. For this purpose, there are stairs accessed from the 5th and 7 th floors. The audience members go out to the 3rd-floor outer stylobate from the stairs outside. There are 12 such access stairs along the stadium perimeter. In Figure 4, the stairs corresponding to the arena northeastern quarter are denoted by STW with a number (see below). In addition, one can come down the straight stairs from the 5th floor directly to the 3rd floor (ST with a number in Figure 4). The audience members descend from the 3rd-floor stylobate to the grade.

It is noteworthy that the main vertical lines are arranged differently from the Colosseum: stairs STW, up to the 6th floor, are located along the perimeter of the bowl aside from its volume (Figure 6), except for the stairs rising to the upper (7th-floor) stylobate level, which partially enter the bowl volume (Figure 7).

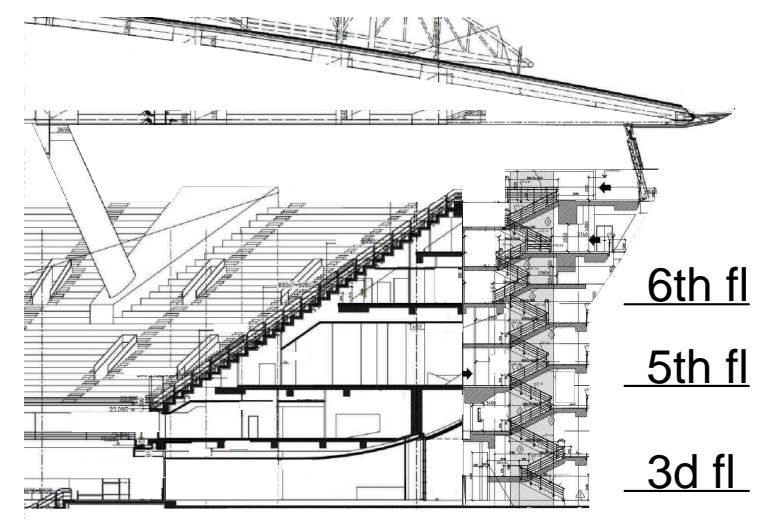

Figure 6. Schematic arrangement of the stairs (STW) relative to the bowl in the Gazprom Arena.

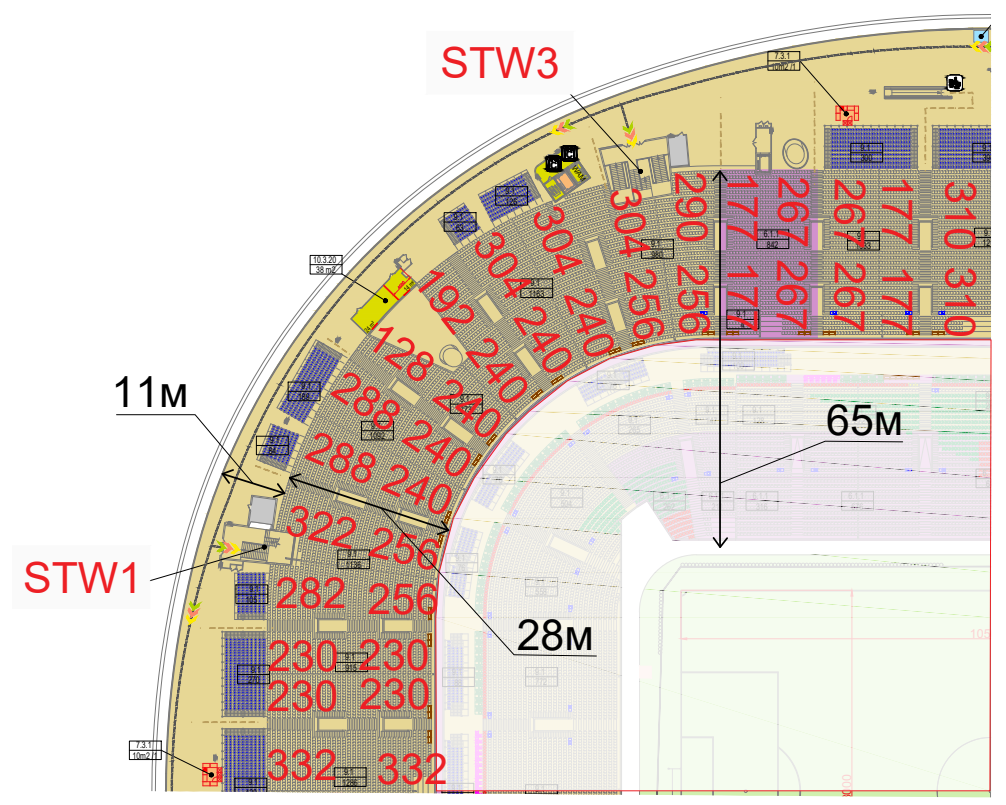

Figure 7. Plan of the Gazprom Arena northeastern part upper bowl. The numbers of people in the sectors entering the 5th and 6th floors, the 7th floor stylobate, and the down stairs are indicated. 
Figure 7 presents a plan of upper bowl sectors of the investigated quadrant. The numbers of people going to the 5th and 6th floors are shown and the stairs that can be used to descend are indicated (STW1 and STW3, see Figure 4).

Figure 8 shows a plan of the 5 th-floor under-stand space. One can see the stairs accessible for descending from the 5th to 3rd floor (STW1, STW2, and STW3) and the straight descents directly to the 3rd-floor outer stylobate (ST1, ST2, and ST3). The arrows show the directions of movement from the hatches to the nearest exits from the floor; the numbers of people for whom the corresponding exit is the nearest one are indicated (the total number of people is 4454).

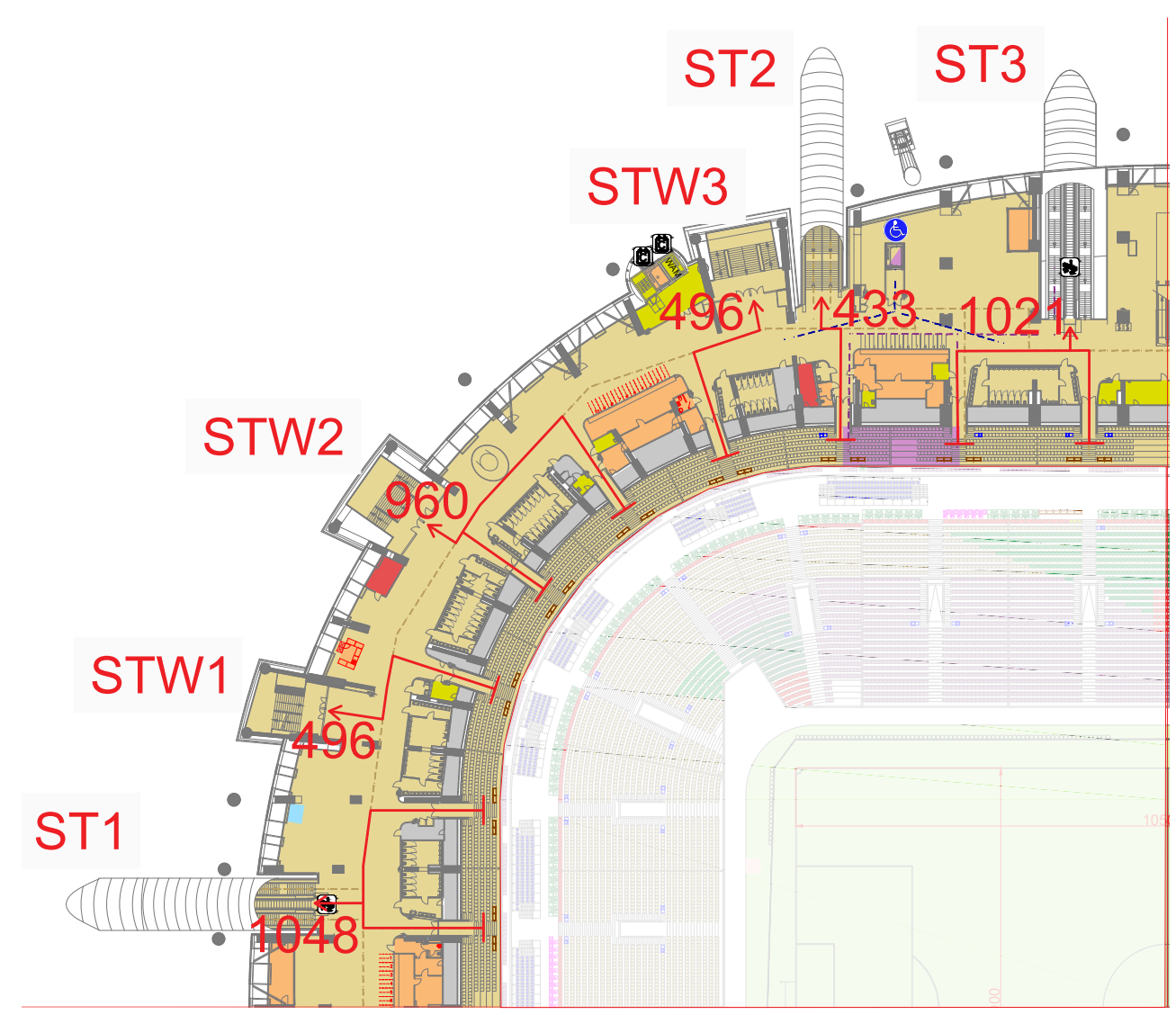

Figure 8. Plan of the northeastern part of the Gazprom Arena 5th floor and distribution of people leaving the bowl through the 5th floor down the nearest stairs.

It should be noted that the stairs are distributed around the 5th floor fairly uniformly. In this case, the loads on the adjacent stairs differ by a factor of up to 2 . The stair-to-sector ratio is $6 / 9$.

Figure 9 presents a plan of the 6th-floor under-stand space. The stairs accessible for descending from the 6th to 3rd floor (STW1, STW2, and STW3) are shown. The arrows point out the directions of movement from the hatches to the nearest exits from the floor; the numbers of people for whom the corresponding exit is the nearest one are indicated.

The analysis of the 6th-floor plan shows that the number of stairs in it twice as small as in the 5th floor, while the number of audience members on the former is greater (4692 in total). The stair-to-sector ratio is $3 / 9$. The stairs are nonuniformly distributed relative to the hatches, the loads on the stairs differ by a factor of more than 2 , and the minimum load is twice as high as that on the 5 th floor.

For further analysis, it is interesting to consider the load on stairs STW1, STW2, and STW3, since they are used by people descending from two (5th and 6th) floors. In addition, the construction of stairs STW1 is significantly different from that of stairs STW2 and STW3 (Figure 10). The quantitative data are given in Table 1. 


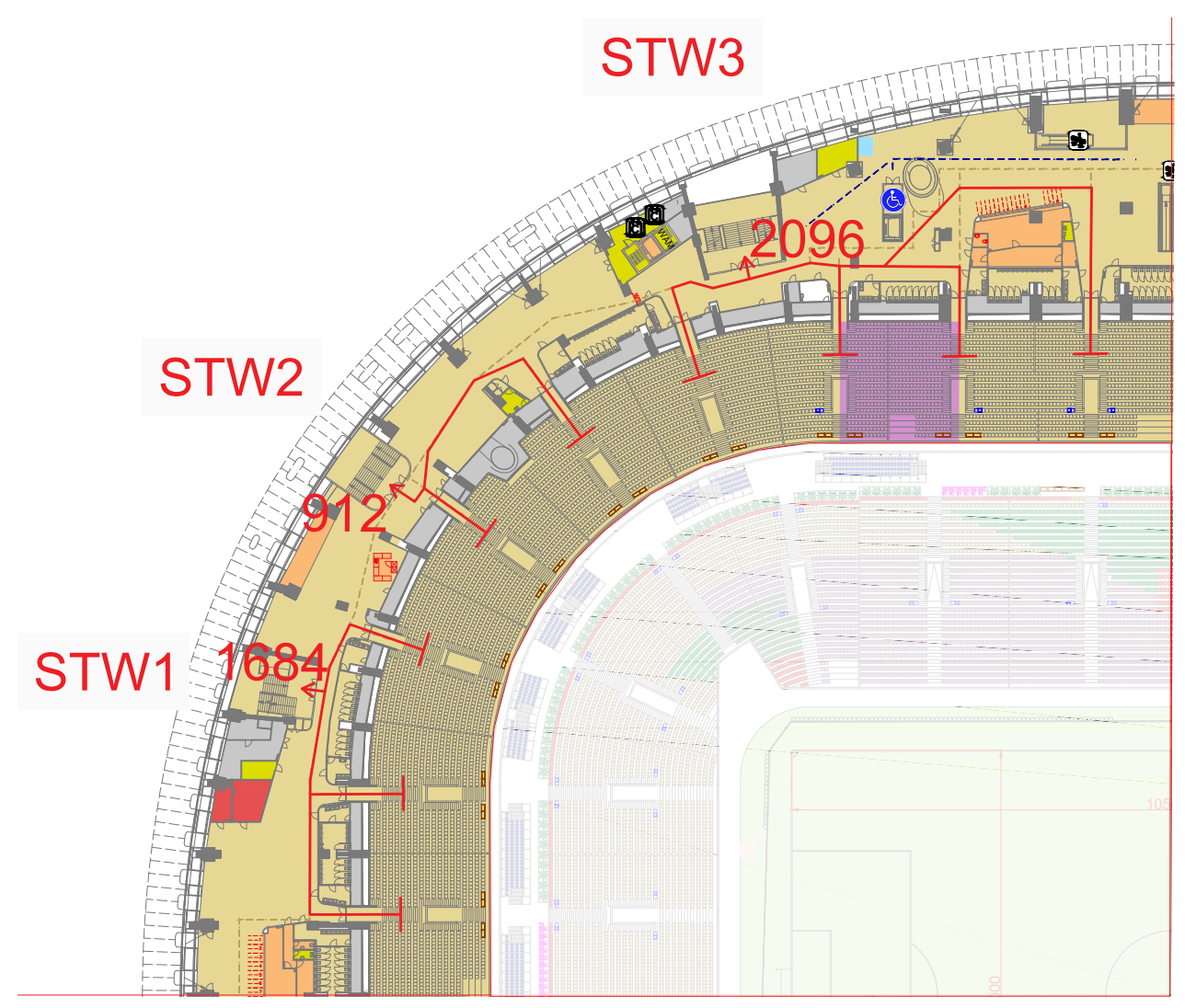

Figure 9. Plan of the northeastern part of the Gazprom Arena 6th floor and distribution of people leaving the bowl through the 6th floor down the nearest stairs.

Table 1. Loads on stairs STW1, STW2, and STW3 and geometric dimensions of the latter.

\begin{tabular}{lllllll}
\hline Stair name & $\begin{array}{l}\text { 5th floor, } \\
\text { persons }\end{array}$ & $\begin{array}{l}\text { 6th floor, } \\
\text { persons }\end{array}$ & $\begin{array}{l}\text { Total, } \\
\text { persons }\end{array}$ & $\begin{array}{l}\text { Minimum } \\
\text { width, } \mathrm{m}\end{array}$ & $\begin{array}{l}\mathrm{I}, \text { Stair length along the } \\
\text { person/m } \\
\text { of width }\end{array}$ & $\begin{array}{l}\text { axis of movement, } \mathrm{m} \\
\text { and }\end{array}$ \\
\hline STW1 & 496 & 1684 & 2180 & 2.6 & 838.5 & 63 \\
STW2 & 960 & 912 & 1872 & 4.0 & 468 & 63 \\
STW3 & 496 & 2096 & 2592 & 4.0 & 648 & 63 \\
Total, persons & 1952 & 4692 & 6644 & & & \\
\hline
\end{tabular}

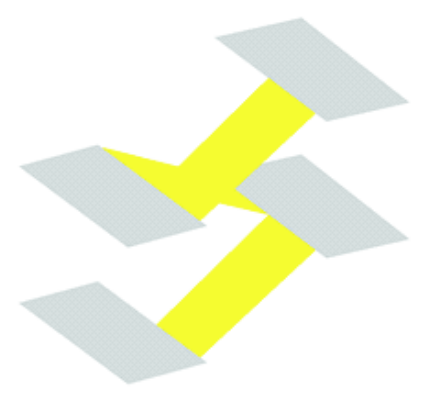

a)

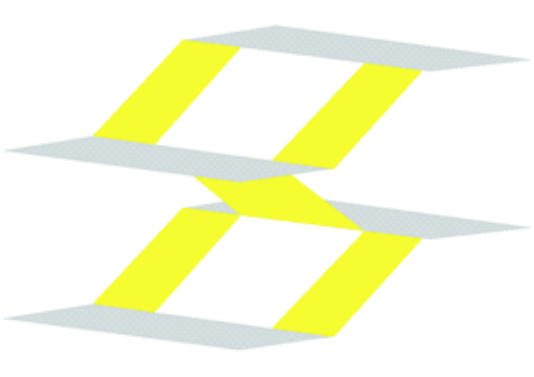

b)

Figure 10. Fragments of the Gazprom Arena stairs: (a) STW1 with a stair flight of $2.6 \mathrm{~m}$ and (b) STW2 and STW3 with stair flight of $4 \mathrm{~m}(2 \mathrm{~m}+2 \mathrm{~m})$.

The minimum path width for stairs STW1 is narrower than for stairs STW2 and STW3 by a factor of 1.5. The ratio between the discharge values for these stairs is the same. Calculating the stairs loading 
according to the nearest stairs principle, we can see that the staircase with the lowest discharge value (STW1) on the 6th floor has an almost maximum load: the stairs take a half of the northern part of the 6th floor. At the same time, the adjacent stairs STW2 with a discharge value greater by a factor of 1.5 are only accessed for two sectors located directly on the corner. The load on stairs STW1 on the 5th floor is reduced by the presence of exit ST1.

\section{Comparative Analysis of the Arenas using the Numerical Simulation of Human Movement}

\subsection{Initial data for the evacuation simulation}

To compare the two arenas, let us consider their parts: a quarter of the Colosseum and a quarter of the Gazprom Arena upper bowl. This is justified by the symmetry of the Colosseum and the Gazprom Arena upper bowl with respect to both axes; in addition, the buildings have comparable capacities (12,000 and 9,500 people, respectively) and, to appear outside both of them, it is necessary to descend.

Figures 11 and 12 show the 3D models built for the arenas. The Gazprom Arena computer model was built using modern drawings. The entire stadium was modeled and used not only within the limits of this study.

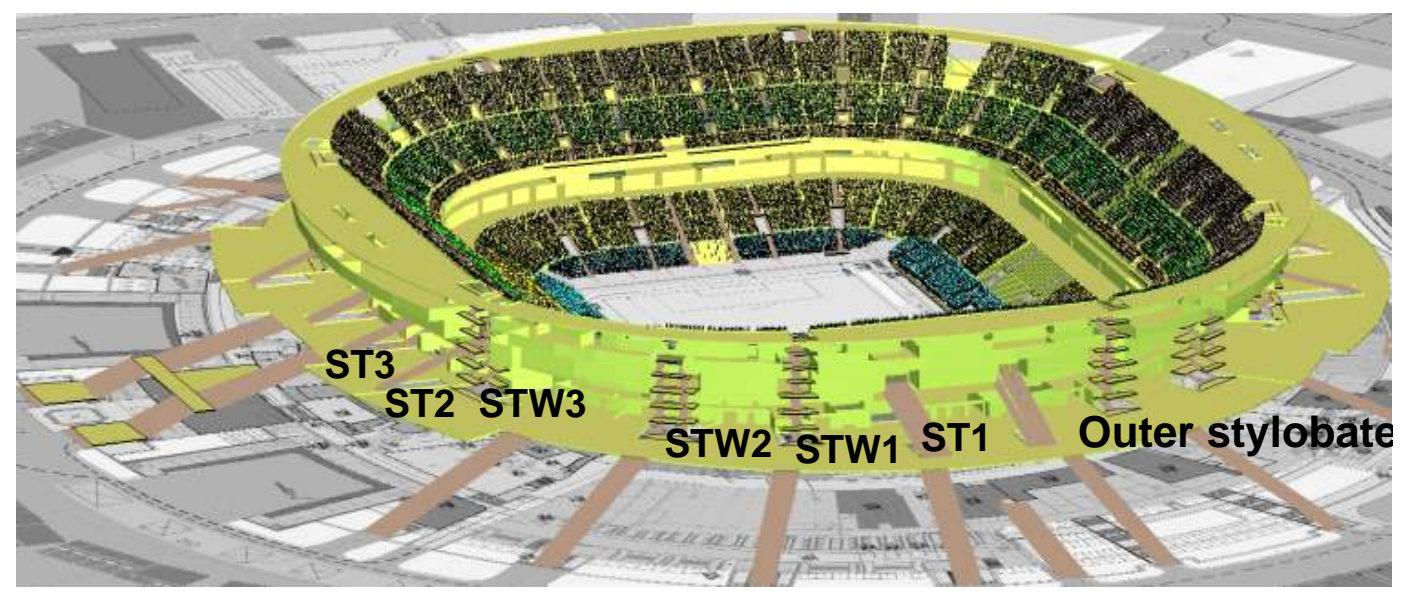

Figure 11. 3D model of the Gazprom Arena stadium (northeastern view) built in the Sigma PB software and seating in the stands.

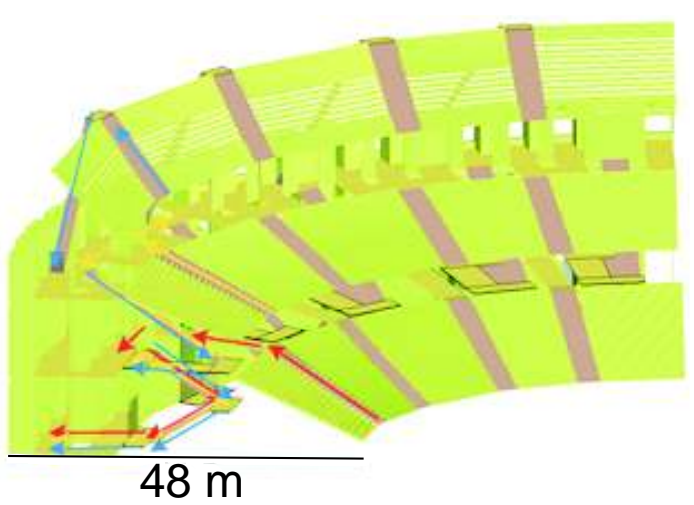

a)

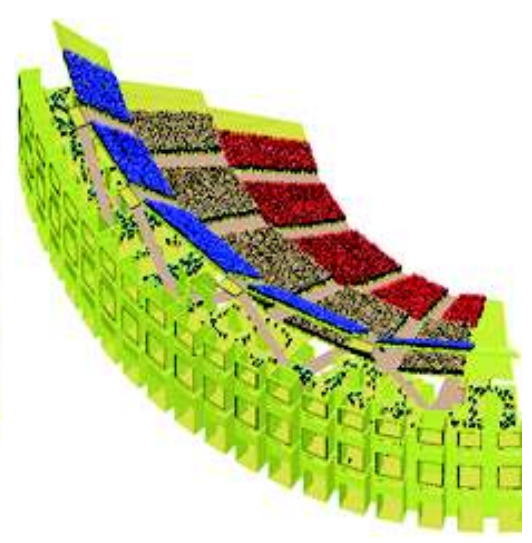

b)

Figure 12. Colosseum 3D model built in the Sigma PB software. Views from the side of (a) the arena and (b) the building facade and audience location in the sectors.

The Colosseum computer model could be built using only rough descriptions. The model was based on the Durm's structural scheme [1]. The attention was mainly paid to the under-stand space 
and the stairs for descending from the upper tiers, since this part of the building affects the evacuation time the most. The analysis of the available sources of information on the Colosseum showed that the arrangement of the stairs for descending from the upper tiers was approximately the same along the arena perimeter. Therefore, when building a computer model, it was necessary to ensure the approximate length and width of each unit path down from the upper floors and the number of paths (stairs).

Many geometrical dimensions of the interior space were taken at a scale relative to the known dimensions given in the drawings. The descriptions provide limited data on the configuration of the stairs used to descend from the upper tier to the 3rd floor. It is known, however, that people from the upper tier merged into the streams of people from the corresponding sectors of the lower tiers. Therefore, the stairs for descending from the upper tier (Figure 12(b)) were conditionally restored to ensure the descent of a number of persons significant for further consideration in the general flow to the 3rd floor. Each sector of the stands on each tier has a staircase for descending from the sector to the underlying floor, where people used the nearest ladder to further descend. The model includes 5 sectors. They are secured by 5 access staircases. To exclude the boundary effects, we analyze the dynamics of human movement in the central part, i.e., in the three central sectors and the three central staircases. For the same reason, the extreme sectors in the model are only half filled (Figure 12(b)).

To analyze and compare the arena designs, we calculated quantitative indicators in comparable situations. In the Colosseum, the dynamics of descent from the 3rd to 1st floor was analyzed (the height difference is $22 \mathrm{~m}$ and the length of the path down stairs is $\sim 63 \mathrm{~m}$ ). In the Gazprom Arena, we investigated the movement of people down stairs from the 6th to 3rd floor (the height difference is $18.3 \mathrm{~m}$ and the staircase length is $\sim 63 \mathrm{~m}$ ).

The quantitative characteristics were obtained using the computer simulation of the movement of people (evacuation) in the Sigma PB software package for the advanced fire and evacuation simulation [18-20]. The software was used to check the designs and organize pedestrian areas for the 2018 FIFA World Cup and the 29th Winter Universiade athletics facilities [21,22].

To simulate the evacuation, an individual flow model was built using the Sigma PB software. The model suggests the calculation of a position of each person, taking into account the positions of other people and obstacles on the plane, and allows one to specify individual characteristics, including the free movement velocity, projected area, path, and movement start time. The individual flow model is best suited for simulating the pedestrian traffic on facilities with stands.

In the calculation, we used the following individual characteristics of persons:

1. The average maximum velocity of free movement of a person was taken to be $1.66 \mathrm{~m} / \mathrm{s}$ [23].

2. The fundamental diagram of the relation between the velocity and the current flow density was borrowed from [23] (we cannot state that this is fully justified for the Colosseum, but this assumption matches the analyzed data in terms of the limiting flow rate and dynamics).

3. The person horizontal projection area used was $0.1 \mathrm{~m}^{2}$ [23]. The differences in gender, age, health status, and other indicators were ignored.

The computational domain involved the stands, under-stand galleries, and stairs. At the initial instant of time, people were in the stands or in the under-stand space. The evacuation of people from the building was simulated before exiting outside at the 1st-floor level for the Colosseum and before exiting beyond the exterior perimeter for the Gazprom Arena (note, however, that here we used the data on leaving the upper bowl before exiting to the 3rd-floor external stylobate).

The computational domain involved the stands, under-stand galleries, and stairs. At the initial instant of time, people were in the stands or in the under-stand space. The evacuation of people from the building was simulated before exiting outside at the 1st-floor level for the Colosseum and before exiting beyond the exterior perimeter for the Gazprom Arena (note, however, that here we used the data on leaving the upper bowl before exiting to the 3rd-floor external stylobate). 


\subsection{Results of the Simulation}

Figures 13 and 14 show fragments of the Colosseum and Gazprom Arena evacuation at the hundredth second from its beginning.

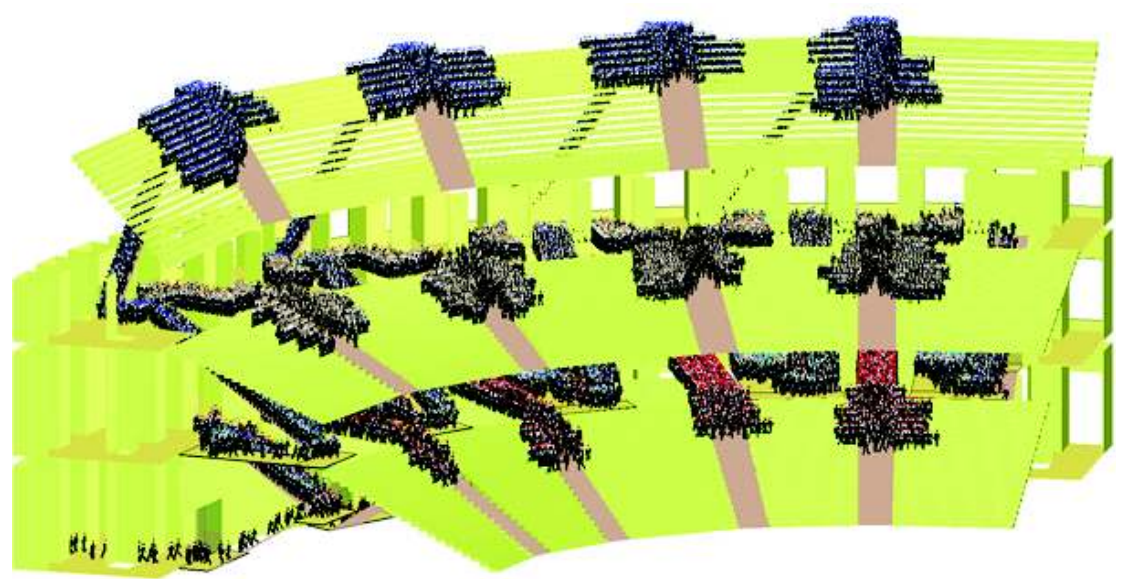

Figure 13. Fragment of the Colosseum evacuation at the hundredth second from its beginning.

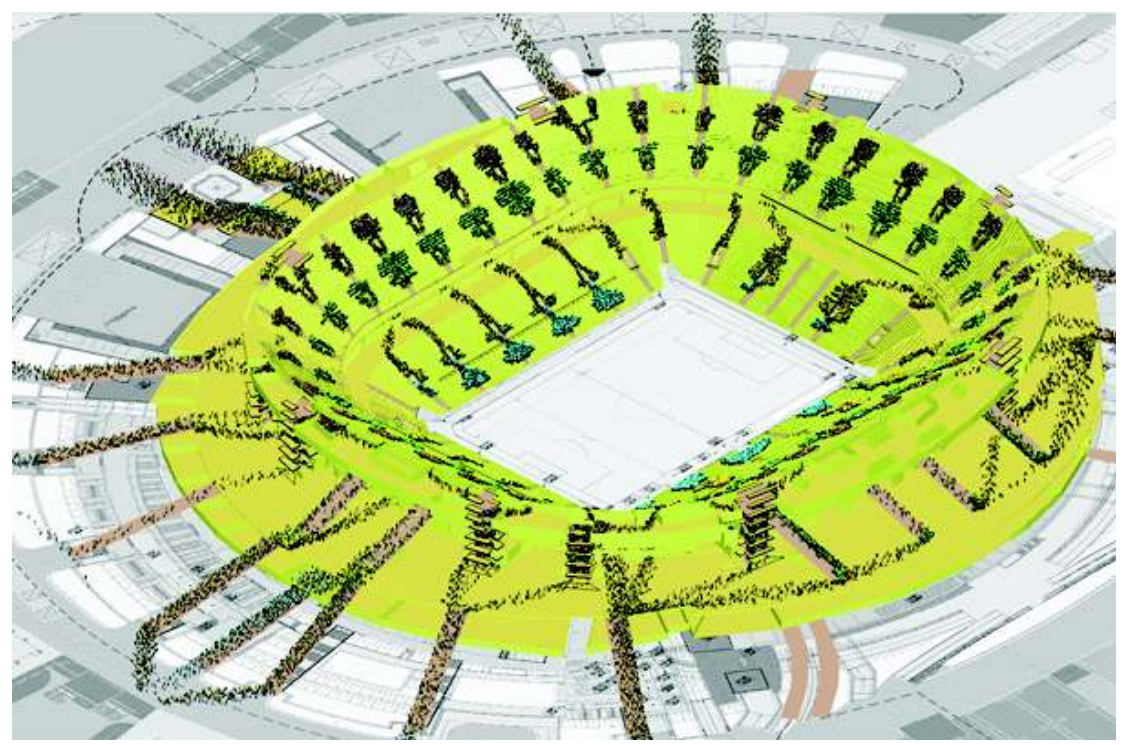

Figure 14. Fragment of the Gazprom Arena evacuation at the hundredth second from its beginning.

For the Gazprom Arena, we made several computations (scenarios) with different loads on stairs STW1 and STW2-3. The data on number $\mathrm{N}$ of the persons who passed the stairs, spent time $t$, and flow rate $\mathrm{Q}(\mathrm{Q}=\mathrm{N} / \mathrm{t}$ [person/s]) are given in Table 2 .

The data given in columns 4 and 7 confirm the expected difference (by a factor of about 2) between the flow intensity estimates for stairs STW1 and STW2-3 by virtue of the similar difference between the path widths. At the similar numbers of persons, the evacuation time for stairs STW1 is twice as long as for stairs STW2-3.

It is worth noting that the capacity of the Colosseum stairs is comparable with that of stairs STW2-3 in the Gazprom Arena. Meanwhile, the staircase width in the Colosseum is smaller by a factor of $\sim 1.5$. This effect is caused by the stairs construction. In the Colosseum, the height difference between the 3rd and 1st floors is $22 \mathrm{~m}$; in the Gazprom Arena, the height difference between the investigated 6th and 3rd floors is $18.3 \mathrm{~m}$. These values can be considered similar. The structure of the Gazprom Arena stairs was accurately reconstructed in the computer model. The main important 
features are that all the stairs connecting the upper floors are outside the bowl. There are eight $180^{\circ}$ turns between the 6th and 3rd floors (a stair flight has an average height difference of $2.1 \mathrm{~m}$ and an average slope of $30^{\circ}$; the flight widths are given in Table 1) (Figure 6).

Table 2. Numerical characteristics of the Colosseum and Gazprom Arena (number $\mathrm{N}$ of the persons who passed the stairs in time $t[s]$, and the flow rate $Q=N / t$ [person/s]).

\begin{tabular}{|c|c|c|c|c|c|c|c|c|c|}
\hline & \multicolumn{6}{|c|}{ Gazprom Arena } & \multirow{3}{*}{\multicolumn{3}{|c|}{$\begin{array}{c}\text { Colosseum } \\
\text { The width is } 2.8 \mathrm{~m} \\
\text { The height difference is } 30 \mathrm{~m}\end{array}$}} \\
\hline & \multicolumn{3}{|c|}{ STW1, the width is $2.6 \mathrm{~m}$} & \multirow{2}{*}{\multicolumn{3}{|c|}{$\begin{array}{l}\text { STW2-3, the width is } 4 \mathrm{~m} \\
\text { rence is } 18.3 \mathrm{~m}\end{array}$}} & & & \\
\hline & \multirow[b]{2}{*}{$\mathrm{N}$} & \multirow[b]{2}{*}{$\mathrm{t}, \mathrm{s}$} & The height difference is $18.3 \mathrm{~m}$ & & & & & & \\
\hline & & & $\begin{array}{l}\text { Q, } \\
\text { person/s }\end{array}$ & $\mathrm{N}$ & $t, s$ & $\begin{array}{l}\text { Q, } \\
\text { person/s }\end{array}$ & $\mathrm{N}$ & $t, s$ & $\begin{array}{l}\text { Q, } \\
\text { person/s }\end{array}$ \\
\hline 1 & 2 & 3 & 4 & 5 & 6 & 7 & 8 & 9 & 10 \\
\hline 1 & 1680 & 990 & 1.7 & 1810 & 520 & 3.5 & 2150 & 705 & 3.1 \\
\hline 2 & 1800 & 1075 & 1.7 & 1970 & 600 & 3.3 & 2405 & 760 & 3.2 \\
\hline 3 & 2030 & 1175 & 1.7 & 1980 & 640 & 3.1 & 2480 & 740 & 3.4 \\
\hline 4 & 2380 & 1400 & 1.7 & 2010 & 660 & 3.0 & 2720 & 840 & 3.2 \\
\hline 5 & 2850 & 1570 & 1.8 & 2150 & 640 & 3.4 & & & \\
\hline 6 & 3580 & 2080 & 1.7 & 2380 & 725 & 3.3 & & & \\
\hline 7 & 3670 & 2025 & 1.8 & 4410 & 1290 & 3.4 & & & \\
\hline 9 & Mean & & 1.7 & Mean & & 3.3 & Mean & & 3.2 \\
\hline
\end{tabular}

To estimate the results obtained for the Colosseum, it should be mentioned that the interior space (in particular, the stairs) has been reconstructed approximately. However, the under-stand space volume on the Colosseum floors, which is still accessible for research, and the data on the under-stand space structure and the axes lengths in the plan allow us to consider the geometry of the Colosseum vertical connections used in the model to be sufficient for this study. In particular, the descent from the 3rd to 2nd floor was reconstructed as straight (without turns, its length is $21.5 \mathrm{~m}$, see Figure 12(a)); it occupies the under-stand space of the second tier. The stair flights going down from the floors are codirected; to get to the next flight, one need to make two $180^{\circ}$ turns. There is one $180^{\circ}$ turn between the 2 nd and 1st floors and there are three turns to make in total when descending from the 3rd and 1st floors; the average flight slope is $30^{\circ}$.

Table 3 generalizes the numerical characteristics of the investigated stairs for the two arenas. The Colosseum stairs are characterized by the highest specific flow (column 5). With conditionally the same length, slope, and height difference parameters, this fact is ensured by the layout of the Colosseum stairs, specifically, by the number of turns (column 6), which is twice as small as in the Gazprom Arena stadium. The result obtained is consistent with the data of a full-scale experiment [24], in which the movement down stairs in a nine-storied building was examined; there were $180^{\circ}$ turns on the stairs and the specific flow decreased with a decrease in the floor (and an increase in the number of turns).

Table 3. Summary table with the numerical characteristics of the Colosseum and Gazprom Arena stairs.

\begin{tabular}{lllllllll}
\hline Stairs & $\begin{array}{l}\text { Width, } \\
\mathrm{m}\end{array}$ & $\begin{array}{l}\mathrm{Q}_{\mathrm{av},} \\
\text { person/s }\end{array}$ & $\begin{array}{l}\mathrm{q}_{\mathrm{av},} \\
\text { person/s/m }\end{array}$ & $\begin{array}{l}\text { Number of } \\
180^{\circ} \text { turns }\end{array}$ & $\begin{array}{l}\text { Height } \\
\text { difference, } \\
\mathrm{m}\end{array}$ & $\begin{array}{l}\text { Length, } \\
\mathrm{m}\end{array}$ & $\begin{array}{l}\text { Slope, } \\
\text { deg }\end{array}$ \\
\hline 1 & 2 & 3 & 4 & 5 & 6 & 7 & 8 & 9 \\
\hline 1 & $\begin{array}{l}\text { Gazprom } \\
\text { Arena, } \\
\text { STW1 } \\
\text { Gazprom }\end{array}$ & 2.6 & 1.7 & 0.65 & 8 & 18.3 & 63 & 30 \\
$\begin{array}{l}\text { Arena, } \\
\text { STW2-3 } \\
\text { Colosseum }\end{array}$ & 2.8 & 3.3 & 0.8 & 8 & 18.3 & 63 & 30 \\
\hline
\end{tabular}


Thus, under other conditions, which can be assumed to be the same or slightly different for the investigated arenas, a key characteristic that determines the building evacuation rate was found to be the geometric characteristic of the stairs determining the number of $180^{\circ}$ turns. The relation between the specific flow and the number of turns is nonlinear. In addition, as can be seen from rows 1 and 2 of column 5, the configuration of the stairs (Figure 10) also affects the flow rate.

\section{Discussion and Conclusions}

In case of fire, the facility's smoke protection system plays a decisive role in ensuring the safe evacuation conditions. According to Technical regulations on fire safety requirements, in Russia, the safe conditions are currently defined by the inequality $t_{\text {evac }}>0.8 t_{\text {block }}$, where $t_{\text {evac }}$ is the time of the end of evacuation from the building area and $t_{\text {block }}$ is the time of reaching the critical value by any of dangerous fire factors ${ }^{2}$.

The most reliable of the smoke protection methods is the use of optimal building and structure designs. Let us consider the designs of the examined arenas in terms of the smoke protection.

The Colosseum is an open structure, where, in case of fire, there are almost no obstacles for spreading the dangerous fire factors, including, first of all, smoke, in the under-stand space; therefore, a decisive factor is the building escape velocity. The high velocity of movement of people from the upper tiers is ensured by the escape routes maximally straightened using the optimal configuration of the stairs and providing each stand with its own down stairs and own exit from the building.

In the Colosseum, the people gathering places with a density of $6\left[\right.$ person $\left./ \mathrm{m}^{2}\right]$ and higher are the exits to the downstairs on the 3rd floor (Figure 15), since the capacity of these stairs is lower than the intensity of flows from the second and third tiers. Therefore, the time of mass gathering on the 3rd floor can be minimized by the phased evacuation.

In the Gazprom Arena, the under-stand space is fenced off from the environment (in contrast to the bowl, which, in general, can be considered open). The smoke protection by the design is implemented via walling off the staircases and making them smoke-free. The availability of downstairs in the Gazprom Arena upper bowl ranges within 1/3-2/3 on different floors. This leads to the discrepancy between the intensities of the suitable flow and the discharge values of the doors on the staircase and causes the long-term (up to $900 \mathrm{~s}$ ) mass gathering (Table 4). The problem can be solved by organizing the phased evacuation. To enhance the efficiency of using the vertical lines, it is necessary to control the human flows on the 5th floor in order to relieve stairs STW1-likewise, which take a significant load in the south and north sectors of the 6th floor.

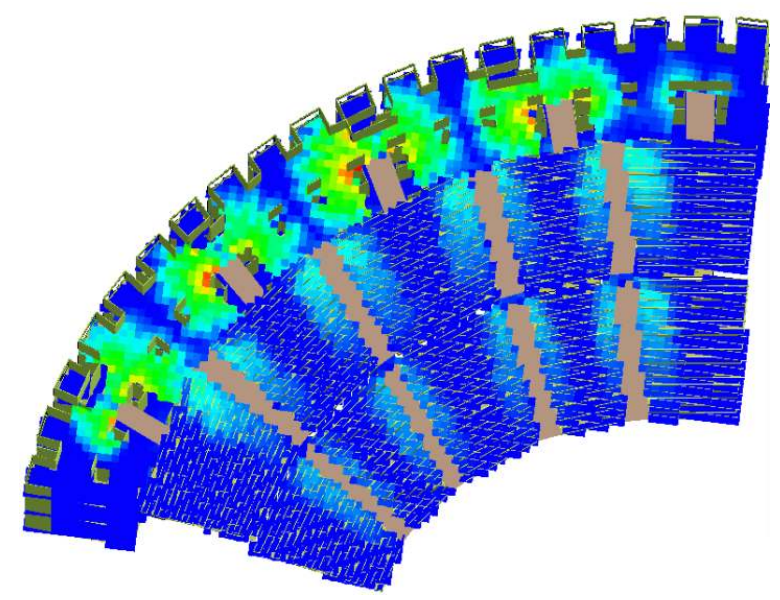

Figure 15. Mass gathering intensity field on the Colosseum 3rd floor.

2 Technical regulations on fire safety requirements. Federal law No. 123-FZ of July 22, 2008 (in Russian). 
Table 4. Summary table of the Colosseum and Gazprom Arena characteristics.

\begin{tabular}{|c|c|c|c|}
\hline & Characteristic & Colosseum & Gazprom Arena \\
\hline 1 & $\begin{array}{l}\text { Minimum downstairs flow rate, } \\
\text { person } / \mathrm{m} / \mathrm{s}\end{array}$ & 1.14 & 0.65 \\
\hline 2 & Number of $180^{\circ}$ turns per stairs & 3 & 8 \\
\hline 3 & Average mass gathering time, $\mathrm{s}$ & 360 & 900 \\
\hline 4 & $\begin{array}{l}\text { Evacuation control (routing) to } \\
\text { balance the load on the stairs and } \\
\text { reduce the time of mass gathering in } \\
\text { front of the stairs }\end{array}$ & not required & required \\
\hline 5 & Stage-by-stage evacuation & not required & not required \\
\hline 6 & $\begin{array}{l}\text { Fencing the escape routes from the } \\
\text { main space }\end{array}$ & no & yes \\
\hline 7 & $\begin{array}{l}\text { Protection against the dangerous fire } \\
\text { factors }\end{array}$ & $\begin{array}{l}\text { Stairs configuration ensuring } \\
\text { the high velocity of } \\
\text { movement }\end{array}$ & $\begin{array}{l}\text { Fenced-off staircases } \\
\text { protected from the spread of } \\
\text { the dangerous fire factors }\end{array}$ \\
\hline 8 & $\begin{array}{l}\text { Free path to the adjacent hatch along } \\
\text { the stand }\end{array}$ & yes & no \\
\hline 9 & $\begin{array}{l}\text { Availability of a staircase for each } \\
\text { stand (stairs/stand) }\end{array}$ & $1 / 1$ & $2 / 3$ (5 floor); $1 / 3$ (6 floor) \\
\hline 10 & Fire resistance & $\begin{array}{l}\text { The evacuation is completed } \\
\text { before the construction } \\
\text { failure }\end{array}$ & $\begin{array}{l}\text { The evacuation is completed } \\
\text { before the construction } \\
\text { failure }\end{array}$ \\
\hline
\end{tabular}

To sum up, through a prism of our investigations, the Colosseum design seems advantageous over the Gazprom Arena. The most significant difference is, perhaps, the higher stability and weak need of the evacuation process in the control factors.

\section{References}

1. Tsires, A.G. Architecture of the Colosseum (In Russian); Moscow: Publishing house of the Academy of architecture of the USSR, 1940; p. 66. In Russian.

2. Kuligowski, E.D., Computer Evacuation Models for Buildings. In SFPE Handbook of Fire Protection Engineering; Hurley, M.J.; Gottuk, D.; Hall, J.R.; Harada, K.; Kuligowski, E.; Puchovsky, M.; Torero, J.; Watts, J.M.; Wieczorek, C., Eds.; Springer New York: New York, NY, 2016; pp. 2152-2180. doi:10.1007/978-1-4939-2565-0_60.

3. Schadschneider, A.; Klingsch, W.; Klüpfel, H.; Kretz, T.; Rogsch, C.; Seyfried, A., Evacuation Dynamics: Empirical Results, Modeling and Applications. In Extreme Environmental Events; Meyers, R.A., Ed.; Springer New York: New York, NY, 2011; pp. 517-550. doi:10.1007/978-1-4419-7695-6_29.

4. Ronchi, E.; Uriz, F.N.; Criel, X.; Reilly, P. Modelling large-scale evacuation of music festivals. Case Studies in Fire Safety 2016, 5, 11 - 19. doi:10.1016/j.csfs.2015.12.002.

5. Pretorius, M.; Gwynne, S.; Galea, E.R. Large crowd modelling: an analysis of the Duisburg Love Parade disaster. Fire and Materials 2015, 39, 301-322. doi:10.1002/fam.2214.

6. Wagoum, A.U.K.; Seyfried, A. Conception, Development, Installation and Evaluation of a Real Time Evacuation Assistant for Complex Buildings. Procedia - Social and Behavioral Sciences 2013, 104, 728 - 736. doi:10.1016/j.sbspro.2013.11.167.

7. Boltes, M.; Seyfried, A. Collecting pedestrian trajectories. Neurocomputing 2013, 100, 127 - 133. doi:10.1016/j.neucom.2012.01.036.

8. Wei, Z.; Hui, D.; Tong, W. The application of fire spread and evacuation simulation technology in large stadium. Stochastic Environmental Research and Risk Assessment 2009, 23. doi:10.1007/s00477-008-0239-1.

9. Dridi, M. Simulation of High Density Pedestrian Flow: A Microscopic Model. Open Journal of Modelling and Simulation 2015, 3, 81-95. doi:10.4236/ojmsi.2015.33009.

10. Khan, S.D.; Vizzari, G.; Bandini, S. A Computer Vision Tool Set for Innovative Elder Pedestrians Aware Crowd Management Support Systems. AI*AAL@AI*IA, 2016, pp. 75-91. 
11. Khan, S.D. Congestion detection in pedestrian crowds using oscillation in motion trajectories. Engineering Applications of Artificial Intelligence 2019, 85, 429 - 443. doi:10.1016/j.engappai.2019.07.009.

12. Shimura, K.; Khan, S.; Bandini, S.; Nishinari, K. Simulation and evaluation of spiral movement of pedestrians: Towards the tawaf simulator. Journal of Cellular Automata 2016, 11, 275-284.

13. Mitsopoulou, M.; Dourvas, N.; Georgoudas, I.G.; Sirakoulis, G.C. Cellular Automata Model for Crowd Behavior Management in Airports. Parallel Processing and Applied Mathematics; Wyrzykowski, R.; Deelman, E.; Dongarra, J.; Karczewski, K., Eds.; Springer International Publishing: Cham, 2020; pp. 445-456. doi:10.1007/978-3-030-43222-5_39.

14. Davidich, M.; Geiss, F.; Mayer, H.G.; Pfaffinger, A.; Royer, C. Waiting zones for realistic modelling of pedestrian dynamics: A case study using two major German railway stations as examples. Transportation Research Part C: Emerging Technologies 2013, 37, 210 - 222. doi:10.1016/j.trc.2013.02.016.

15. Wang, W.L.; Lo, S.M.; Liu, S.B.; Ma, J. On the Use of a Pedestrian Simulation Model with Natural Behavior Representation in Metro Stations. Procedia Computer Science 2015, 52, 137 - 144. doi:10.1016/j.procs.2015.05.048.

16. Trivedi, A.; Pandey, M. Agent Based Modelling and Simulation to estimate movement time of pilgrims from one place to another at Allahabad Jn. Railway Station during Kumbh Mela-2019. Autonomous Agents and Multi-Agent Systems 2020, 34. doi:10.1007/s10458-020-09454-x.

17. Gravit, M.; Dmitriev, I.; Kuzenkov, K. Phased evacuation algorithm for high-rise buildings. MATEC Web of Conferences 2018, 245, 11012. doi:10.1051/matecconf/201824511012.

18. Kirik, E.; Vitova, T.; Malyshev, A.; Popel, E. A Conjunction of the Discrete-Continuous Pedestrian Dynamics Model SigmaEva with Fundamental Diagrams. Parallel Processing and Applied Mathematics; Wyrzykowski, R.; Deelman, E.; Dongarra, J.; Karczewski, K., Eds.; Springer International Publishing: Cham, 2020; pp. 457-466. doi:10.1007/978-3-030-43222-5_40.

19. Kirik, E.; Litvintsev, K.; Dekterev, A.; Khasanov, I.; Gavrilov, A.; Malyshev, A.; Harlamov, E.; Popel, E. Simulations of fire evacuations in "Sigma FS" software as a fire safety training instrument. Proceedings of the Ninth International Seminar on Fire and Explosion Hazards; Snegirev, A., Ed., 2019, pp. 1281-1292. doi:10.18720/SPBPU/2/k19-120.

20. Kirik, E.; Vitova, T. Pedestrian movement: analysis of real experiments in a straight corridor and validation of "Sigma SF" Software (In Russian). Fire Safety 2020, 1, 51-62.

21. Kirik, E.; Malyshev, A. Computer Simulation of Pedestrian Flows for Universiade 2019 Sport Facilities Versus Hand Calculations. Proceedings of Pedestrian and Evacuation Dynamics 2016, Collective Dynamics; Song, W.; Ma, J.; Fu, L., Eds., 2016, pp. 446-454. doi:10.17815/CD.2016.11.

22. Kirik, E.; Malyshev, A.; Vitova, T.; Popel, E.; Kharlamov, E. Pedestrian movement simulation for stadiums design. IOP Conference Series: Materials Science and Engineering 2018, 456, 012074. doi:10.1088/1757-899x/456/1/012074.

23. Kholshevnikov, V. Forecast of human behavior during fire evacuation. Proceedings of the International conference "Emergency evacuation of people from buildings — EMEVAC"; Jaskółowski, W.; Keȩpka, P., Eds. Warsaw: Belstudio, 2011, pp. 139-153.

24. Huo, F.; Song, W.; Chen, L.; Liu, C.; Liew, K. Experimental study on characteristics of pedestrian evacuation on stairs in a high-rise building. Safety Science 2016, 86, 165 - 173. doi:10.1016/j.ssci.2016.02.025. 